\title{
Pulmonary hemorrhage, a rare complication in a girl with Henoch-Schönlein purpura
}

\author{
Gokce Gur, M.D. ${ }^{a}$, Nilgun Cakar, Assoc. Prof. ${ }^{a, b}$, Saba Kiremitci, M.D. ${ }^{c}$, Aysel Taktak, M.D. ${ }^{a}$, \\ Ozge Basaran, M.D..$^{b}$ and Nermin Uncu, M.D..$^{a, b}$
}

\begin{abstract}
Henoch-Schönlein purpura (HSP) is the most common vasculitis in children. Vasculitic processes can involve thelung. Although diffuse alveolar hemorrhage may be seen as one of the manifestation of HSP, it is not a frequent presentation. Here we reported the case of a 10-year-old girl with HSP nephritis who developed pulmonary hemorrhage. The patient was treated successfully with intravenous methylprednisolone. A review of the literature revealed that young age may be a good prognostic sign and that immunosuppressive drugs and supportive management are essential in the treatment.

Key words: Henoch-Schönlein purpura, pulmonary, alveolar hemorrhage, child.
\end{abstract}

http:/ /dx.doi.org/10.5546/aap.2016.eng.e366

\section{INTRODUCTION}

Henoch-Schönlein purpura (HSP) is characterized by non-thrombocytopenic purpura on the lower extremities, abdominal pain, renal involvement, typical histopathology, arthritis and arthralgia. ${ }^{1}$ It is the most common vasculitis seen in children. Pulmonary involvement is rare and it significantly increases the mortality. ${ }^{2}$ There are few reports regarding pulmonary hemorrhage in HSP.

a. Department of Pediatric Nephrology, Ankara Child Health, Hematology, Oncology Education and Research Hospital, Ankara, Turkey.

b. Department of Pediatric Rheumatology, Ankara Child Health, Hematology, Oncology Education and Research Hospital, Ankara, Turkey.

c. Department of Pathology, Ankara Medical School, Ankara, Turkey.

E-mail Address:

Ozge Basaran, M.D.: ozgesalor@yahoo.com

Funding: None.

Conflict of interest: None.

Received: 2-20-2016

Accepted: 4-25-2016

\section{CASE REPORT}

A 10-year-old-girl presented with purpuric rash on the extensor surface of the lower and upper limbs. Two days later, she began with abdominal pain and periorbital edema. Her past and family histories were unremarkable. At presentation, she showed a weight of $29 \mathrm{~kg}$, normal vital signs, blood pressure $130 / 80 \mathrm{mmHg}$, purpuric rash on the extensor surface of the limbs and periorbital edema; the rest of her examination was normal.

Laboratory tests showed hemoglobin $10.9 \mathrm{~g} / \mathrm{dl}$, platelets $365,000 / \mathrm{mm}^{3}$, white blood cells (WBC) $10,900 / \mathrm{mm}^{3}$, prothrombin time $14 \mathrm{~s}$, activated partial thromboplastin time $28 \mathrm{~s}$, serum sodium $134 \mathrm{mmol} / \mathrm{L}$, potassium $5 \mathrm{mmol} / \mathrm{L}$, urea $110 \mathrm{mg}$ / $\mathrm{dl}$, and creatinine $0.93 \mathrm{mg} / \mathrm{dl}$. Total protein $5.0 \mathrm{~g} /$ $\mathrm{dl}$, albumin $2.3 \mathrm{~g} / \mathrm{dl}$; AST and ALT values were normal. The stool occult blood was negative. $\operatorname{IgA}$, $\mathrm{IgG}$ and $\mathrm{IgM}$ values were within normal ranges; $\mathrm{HBsAg}$, anti-HCV Ab, ANA, anti dsDNA, ANCA were negative; anti-HBs $\mathrm{Ab}$ was positive. $\mathrm{ASO}$ was 135 U. Urinalysis showed protein $4+$, red blood cells $>45$ per high-power field (HPF), and WBC 15-20 per HPF. Proteinuria was $204 \mathrm{mg} / \mathrm{m}^{2} /$ hour.

A kidney biopsy performed and the histopathology examination of the biopsy revealed a diffuse proliferative glomerular pathology with diffuse endocapillary hypercellularity, extensive mesangial proliferation and focal extracapillary proliferation as cellular crescents. Leucocyte exudation and karyorrhexis was noted in some of the glomeruli. Hyalin deposits in the peripheral glomerular basement membrane (GBM) similar to classical wire loop lesion of lupus nephritis was remarkable and represented the massive accumulation of immune complexes (Figure 1a). In accordance with this histologic feature, immunofluoresence microscopy revealed diffuse IgG, IgA, C3 deposits among the peripheral GBM, and less intense $\mathrm{C} 1 \mathrm{q}$ and fibrinogen deposits both in mesangium and GBM. IgG deposits were also positive in the mesangium (Figure 1b). The biopsy was reported with a descriptive diagnosis as "proliferative glomerular pathology with diffuse endocapillary and focal extracapillary 
proliferation" with a comment indicating mesangial proliferative glomerulanephritis like pathologic features. With the negativity of lupus serologic indicators and the thorough clinical presentation of HSP, it was interpreted as diffuse proliferative subtype of HSP nephritis. According to the pathology results, a therapy was initiated including pulse intravenous methylprednisolone (MP) (30 mg/ kg/day) for 3 days followed by 2 $\mathrm{mg} / \mathrm{kg} /$ day oral prednisolone, $2 \mathrm{mg} / \mathrm{kg} /$ day oral cyclophosphamide, $5 \mathrm{mg} / \mathrm{kg}$ / day acetylsalicylic acid, $5 \mathrm{mg} / \mathrm{kg} /$ day dipyridamole, and $0.05 \mathrm{mg}$ / $\mathrm{kg} /$ day enalapril.

The patient was re-admitted due to fever three weeks after discharge. The physical examination revealed a $38{ }^{\circ} \mathrm{C}$ body temperature, $120 \mathrm{rpm}$ pulse rate, and $85 / 55 \mathrm{mmHg}$ blood pressure, and the patient had a pale and weak appearance. $\mathrm{Hb} 7.3 \mathrm{~g} / \mathrm{dl}$, platelets $291,000 / \mathrm{mm}^{3}$, WBC 1700 / $\mathrm{mm}^{3}$, urea $48 \mathrm{mg} / \mathrm{dl}$, and creatinine $0.8 \mathrm{mg} / \mathrm{dl}$. Cyclophosphamide therapy was discontinued at day 52 due to reduced WBC count, and intravenous cefotaxime and amikacin were initiated. On the fifth day of antibiotherapy, the patient developed respiratory distress, tachypnea, and tachycardia. Oxygen saturation was $70 \%$, and arterial blood gases analysis showed hypoxemia. $\mathrm{D}$-dimer was normal. Chest X-ray showed diffuse pulmonary infiltrate (Figure 2) and thorax CT showed widespread areas of atelectasis, nodular reticular densities, and patchy ground-glass opacities (Figure 2). Electrocardiography showed sinus tachycardia, echocardiography showed mild mitral valve insufficiency related to tachycardia; systolic and diastolic functions, pulmonary artery and its branches appeared normal.

The diagnosis of pulmonary involvement in HSP, known as diffuse alvolar hemorrhage (DAH) was considered because of the sudden drop of hemoglobin and newly developed pulmonary infiltrates with the lack of cardiac pathology, normal pulmonary artery pressures and D-dimer values, lack of growth in cultured media, and laboratory tests showing negative for Epstein B virus and parvovirus B.

Pulse methylprednisolone was administered (30 mg/ kg/day) for 3 days. Clinical findings and pulmonary infiltrates showed rapid recovery 12 hours after the first dose of pulse MP. The treatment was continued with $2 \mathrm{mg} / \mathrm{kg} /$ day oral prednisolone for one month and it was continued daily with tapering doses following months. Three days pulse MP treatment was repeated every four weeks for six month. Because of the cumulative doses of cyclophosphamide reached to $150 \mathrm{mg} / \mathrm{kg}$ it was not restarted.

At the end of the six month of pulse MP treatment, her blood pressure, hemoglobine, urinalysis, serum biochemistry for serum albumin, urea and creatinine all were normal.

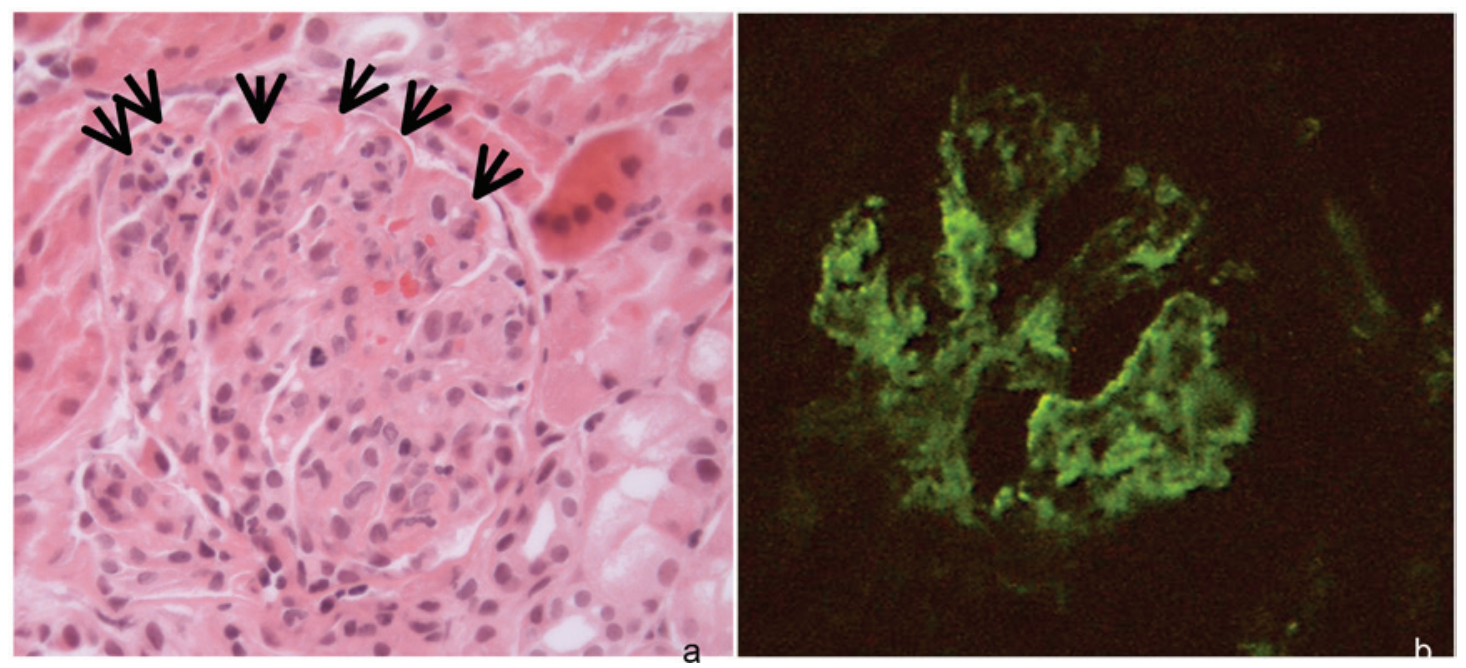

a. Hyperlobular glomeruli reveal extensive mesangial and endocapillary proliferation. Hyalin deposits, seen as eosinophilic material, in the peripheral GBM indicate the immuno complex accumulation (arrows). Hematoxylin and Eosin x200. b. IgG deposits both in peripheral GBM and mesangium is seen by immunofluoresence microscopy. IFMx200. 


\section{DISCUSSION}

Henoch-Schönlein purpura is the most common type of vasculitis in childhood. Skin involvement is evident in all patients. The incidence of joint involvement is $82 \%$, gastrointestinal involvement is seen in $50-75 \%$ of cases, renal involvement is seen in $20-60 \%$ of the cases; urogenital, neurological and pulmonary involvements are observed in $27 \%, 2 \%$, and $1 \%$ of the cases, respectively. ${ }^{1,2}$

Previous reports of pulmonary involvement in HSP have included vasculitis/capillaritis, diffuse $\mathrm{DAH}$, and interstitial fibrosis. Also, isolated decrease in carbon monoxide diffusing capacity in conjunction with subtle radiological signs of interstitial lung involvement in the absence of pulmonary symptoms has been noted in patients with HSP. ${ }^{3}$

Diffuse alveolar hemorrhage is an unusual complication of HSP and data on its frequency, management, and outcomes are scant.

According to HSP EULAR/PRINTO/ PRES Ankara 2008 classification, alveolar hemorrhage considered when at least 2 of the following findings documented; drop in hemoglobin, hemoptysis, new pulmonary infiltrates, hemosiderin-laden macrophages on bronchoalveolar lavage fluid, or surgical or autopsy specimens showing alveolar hemorrhage with or without leukocytoclastic vasculitis. ${ }^{1}$
DAH manifests with systemic complaints and findings (weakness, fever, weight loss, joint pain, skin rash), intra-alveolar erythrocyte deposition as a result of circulating immune complexes and disruption of alveolar-capillary membrane and associated anemia, hemoptysis, hypoxemic respiratory failure, and patchy, focal or widespread pulmonary infiltrations on imaging. ${ }^{4}$

Standard treatment for pulmonary hemorrhage associated with HSP has not been established. For the treatment of HSP accompanied by pulmonary hemorrhage, the majority of previous reports ${ }^{1,5,6}$ suggest that the active use of steroids (oral prednisone or pulse methylprednisolone), immunosuppressant (cyclophosphamide, azathioprine and cyclosporine A) are able to markedly reduce the mortality rate. ${ }^{2,5,7,8}$ Chen et al. summarized the pediatric HSP associated pulmonary hemorrhage patients in the literature. They reported that all patients without respiratory failure survived after treatment by steroid pulse therapy only, steroid pulse therapy plus cyclosporine A, or steroid plus low-dose cyclophosphamide. Considering the possibly significant adverse effects of immunosuppressant therapy, they suggested that steroid therapy be the first-line treatment for these patients when no respiratory failure is present. ${ }^{6}$
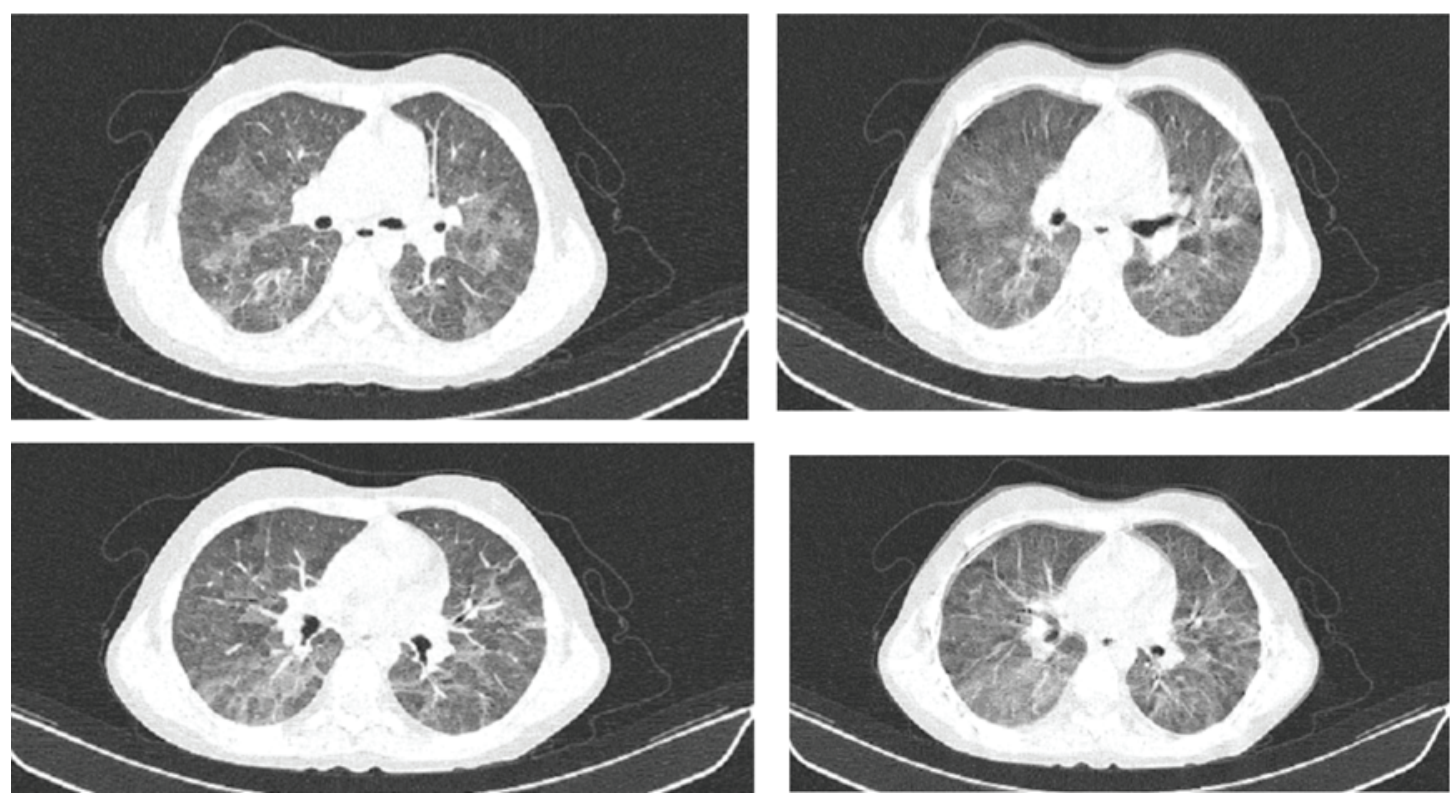

Reticular densities and patchy ground-glass opacities are visible. 
While the patient was receiving oral steroids due to renal involvement, she developed respiratory distress secondary to pulmonary hemorrhage. Oral cyclophosphamide was discontinued because of the reduced white blood cell count. Therefore, we administered pulse MP therapy and the patient responded well in a very short period.

In a meta-analysis published in 2013, mean age of 36 patients with HSP, who developed $\mathrm{DAH}$, was 16.5 years, prevalence was $0.8-5 \%$, and $95 \%$ had renal involvement. In patients with alveolar hemorrhage, the incidence of pulmonary infiltrations was $94 \%$, the incidence of reduced hemoglobin levels was $74 \%$, and mortality rate was $28 \%{ }^{2}$

DAH is a life-threatening complication in HSP, and early diagnosis and treatment saves lives. Pulmonary symptoms, anemia, and infiltrations on chest X-ray in patients with Henoch-Schönlein Purpura should prompt the consideration of $\mathrm{DAH}$ in the diagnosis.

\section{REFERENCES}

1. Ozen S, Pistorio A, Iusan SM, Bakkaloglu A, et al. EULAR/ PRINTO/PRES criteria for Henoch-Schönlein purpura, childhood polyarteritis nodosa, childhood Wegener granulomatosis and childhood Takayasu arteritis: Ankara 2008. Part II: Final classification criteria. Ann Rheum Dis 2010;69(5):798-806.

2. Rajagopala S, Shobha V, Devaraj U, D'Souza G, et al. Pulmonary hemorrhage in Henoch-Schönlein purpura: case report and systematic review of the english literature. Semin Arthritis Rheum 2013;42(4):391-400.

3. CazzatoS, Bernardi F, CintiC, Tassinari D, et al. Pulmonary function abnormalities in children with Henoch-Schönlein purpura. Eur Respir J 1999;13(3):597-601.

4. Castañer E, Alguersuari A, Andreu M, Gallardo X, et al. Imaging findings in pulmonary vasculitis. Semin Ultrasound CT MR 2012;33(6):567-79.

5. Al-Harbi NN. Henoch-Schönlein nephritis complicated with pulmonary hemorrhage but treated successfully. Pediatr Nephrol 2002;17(9):762-4.

6. Chen SY, Chang KC, Yu MC, Asueh S, et al. Pulmonary hemorrhage associated with Henoch-Schönlein purpura in pediatric patients: case report and review of the literature. Semin Arthritis Rheum 2011;41(2):305-12.

7. Usui K, Ochiai T, Muto R, Abe I, et al. Diffuse pulmonary hemorrhage as a fatal complication of Schönlein-Henoch purpura. J Dermatol 2007;34(10):705-8.

8. Matsubayashi R, Matsubayashi T, Fujita N, Yokota T, et al. Pulmonary hemorrhage associated with Henoch-Schönlein purpura in a child. Clin Rheumatol 2008;27(6):803-5. 